\title{
Resin-dentin bond stability and physical characterization of a two-step self-etching adhesive system associated with $\mathrm{TiF}_{4}$
}

\author{
Gabriele Barbosa Torres ${ }^{a}$, Tânia Mara da Silva ${ }^{b}$, \\ Rosanna Tarkany Basting ${ }^{c}$, Enrico Coser Bridi ${ }^{a}$, Fabiana Mantovani Gomes \\ França $^{a}$, Cecilia Pedroso Turssi ${ }^{a}$, Flávia Lucisano Botelho do Amaral ${ }^{a}$, \\ Sérgio Eduardo de Paiva Gonçalves ${ }^{b}$, Roberta Tarkany Basting ${ }^{a, *}$ \\ a São Leopoldo Mandic Dental School and Research Center, Rua José Rocha Junqueira 13, Bairro Swift, Campinas, \\ CEP: 13045-755, São Paulo, Brazil \\ ${ }^{\mathrm{b}}$ Institute of Science and Technology of São José dos Campos, UNESP-Universidade Estadual Paulista, Avenida \\ Engenheiro Francisco José Longo, 777, Jardim São Dimas, São José dos Campos, CEP: 12245-000, São Paulo, Brazil \\ c Faculty of Medical Science (FCM), University of Campinas (UNICAMP), Rua Tessália Vieira de Camargo, 126 - \\ Cidade Universitária Zeferino Vaz, Campinas, CEP: 13083-887, São Paulo, Brazil
}

\section{A R T I C L E I N F O}

Article history:

Received 16 March 2017

Received in revised form

25 June 2017

Accepted 13 July 2017

\section{Keywords:}

Adhesive system

Degree of conversion

Dentin

Dynamic light scattering

Hydrolytic degradation

Microshear bond strength

Titanium tetrafluoride

\begin{abstract}
A B S T R A C T
Objectives. To evaluate the bond strength to superficial (SD) and deep (DD) dentin after the use of $2.5 \%(\mathrm{~T} 2.5 \%)$ or $4 \%$ ( $\mathrm{T} 4 \%$ ) titanium tetrafluoride $\left(\mathrm{TiF}_{4}\right)$ in aqueous solution as a dentin pretreatment, or when incorporated into the primer (T2.5\%P and $\mathrm{T} 4 \% \mathrm{P})$ of an adhesive system (Clearfil SE Bond/CL). Degree of conversion (DC), particle size (PS), polydispersity index (PI) and zeta potential (ZP) of the solutions were evaluated.

Methods. Fifty molars were sectioned longitudinally to obtain two slices of each tooth, which were demarcated into SD and DD. Treatments were applied ( $\mathrm{n}=10$ ): CL; T2.5\%; T4\%; T2.5\%P; T4\%P. After $24 \mathrm{~h}$ or 180 days storage, microshear bond strength tests were performed. The DC values of T2.5\%P and T4\%P were evaluated by FTIR. PS, PI and ZP were measured using dynamic light scattering.

Results. Analysis of mixed models showed significant effect of concentration of $\mathrm{TiF}_{4}{ }^{*}$ solution * storage time $(p=0.0075)$. There were higher bond strength values in SD than in DD $(p=0.0105)$ for all treatments in both times. The failure mode showed adhesive failures in the majority of groups, irrespective of depth and time $(p=0.3746)$. The bond strength values were not affected by treatments. Lower average particle size was observed for $\mathrm{T} 2.5 \% \mathrm{P}$ and $\mathrm{T} 4 \% \mathrm{P}$ at baseline. $\mathrm{T} 2.5 \%$ and $\mathrm{T} 4 \%$ showed a trend towards agglomeration.

Significance. Higher bond strength values were achieved at SD for all treatments and times. The failure modes observed were adhesive. $\mathrm{TiF}_{4}$ incorporation did not affect DC. T2.5\%P and T4\%P presented excellent stability over time.

@ 2017 The Academy of Dental Materials. Published by Elsevier Ltd. All rights reserved.
\end{abstract}

\footnotetext{
* Corresponding author at: Faculdade e Centrode Pesquisas São Leopoldo Mandic/Departamento de Odontologia Restauradora—Dentística Rua José Rocha Junqueira, 13, Bairro Swift, Campinas, CEP: 13045-755, São Paulo, Brazil. Fax: +55 1932113600.

E-mail addresses: gabrielebtorres@hotmail.com (G.B. Torres), tania.silva@ict.unesp.br (T.M. da Silva), rosannatb@gmail.com (R.T. Basting), enricobridi@gmail.com (E.C. Bridi), biagomes@yahoo.com (F.M.G. França), cecilia.turssi@gmail.com (C.P. Turssi), flbamaral@gmail.com (F.L.B. do Amaral), sergio@ict.unesp.br (S.E. de Paiva Gonçalves), rbasting@yahoo.com (R.T. Basting). http://dx.doi.org/10.1016/j.dental.2017.07.016 0109-5641/@ 2017 The Academy of Dental Materials. Published by Elsevier Ltd. All rights reserved.
} 


\section{Introduction}

Dentin biomodifiers and dentin pretreatment agents have been proposed for the purpose of reducing hybrid layer degradation, inhibiting the action of metalloproteinases present in the dentin matrix, diminishing the incidence of secondary caries lesions, and acting on bond strength stability [1,2]. Among the dentin pretreatment agents, the application of an aqueous solution of titanium tetrafluoride $\left(\mathrm{TiF}_{4}\right)$ promotes the formation of a massive structure composed of titanium oxides or organometallic complexes, and a stable, modified, acid resistant smear layer $[3,4]$. It is suggested that the incorporation of $\mathrm{TiF}_{4}$ in the hybrid layer formed by adhesives could enhance the underlying dentin by tissue-specific biomodification with greater durability [4]. This $\mathrm{TiF}_{4}$ solution has been used in studies that evaluated the anticariogenic $[5,6]$ and antierosive $[7,8]$ effect, with concentrations varying from $2.5 \%$ to $4 \%$, which can suggest that these concentrations may also be used as dentin pretreatment.

Dündar et al. [9] verified that pretreatment with an aqueous solution of $2.5 \%$ titanium tetrafluoride $\left(\mathrm{TiF}_{4}\right)$ interfered in the bond strength of adhesive cements to dentin. For etchand-rinse adhesive systems, Devabhaktuni and Manjunath [10] observed that the application of a $4 \%$ aqueous solution of $\mathrm{TiF}_{4}$ before or after acid etching when using a 3-step adhesive system had no influence on the bond to dentin, whereas Tranquilin et al. [11] verified that the use of pretreatment with $2.5 \% \mathrm{TiF}_{4}$ promoted higher bond strength values of a two-step adhesive system to dentin. In addition, a hybrid layer micromorphology with the formation of more numerous and larger diameter tags was obtained, showing the favorable effects of using this pretreatment.

For self-etching adhesive systems, dentin pretreatment with $2.5 \% \mathrm{TiF}_{4}$ may not interfere in the values of bond strength to dentin [12-14], possibly due to the fact that these adhesives have moderate to slight degrees of acidity, and may penetrate through the glaze-like layer formed after the application of $\mathrm{TiF}_{4}$, although the micromorphology of the hybrid layer can be affected with the presence of tags in smaller diameter and depth. However, the differences in $\mathrm{TiF}_{4}$ concentrations used ( 2.5 or $4 \%$ ) to be applied as dentin pretreatment has not yet been elucidated.

It should be considered that aqueous solutions of $\mathrm{TiF}_{4}$ for pretreatment are unstable [15], and there may be the formation of agglomerates, as demonstrated by Basting et al. [14] when using concentration of $2.5 \%$. Therefore, the incorporation of $\mathrm{TiF}_{4}$ into the primer of the two-step self-etching adhesive system may be an alternative for seeking the greater stability of the product and making it easy to use, reducing the clinical steps, and observing that it does not appear to have any influence on the bond strength to superficial dentin, or the degree of conversion [14], suggesting that future studies use $\mathrm{TiF}_{4}$ incorporated into the primer.

However, the bond of adhesive systems to deep dentin has been reported to be lower than the values shown for superficial dentin $[16,17]$ due to the lower quantity of intertubular dentin and collagen fibrils, and larger quantity of water [18] in deep dentin. Therefore, it would appear that intertubular dentin pays an important role during hybrid layer formation, sine the bond strength is directly proportional to the quantity of intertubular dentin available for bonding [19]. Moreover, it must be considered that over time, the bond may be harmed due to the presence of matrix metalloproteinases (MMPs), especially the gelatinases of the MMP-2 and MMP-9 types that lead to hybrid layer degradation [20-22]. Niu et al. [23] observed that MMP-2 was more concentrated in deep dentin and at the amelo-dentin junction, while MMP-9 presented a decreasing distribution from deep dentin in the direction towards superficial dentin, capable of influencing the longevity of the bond in the different depths of the dentin substrate [24].

Therefore, the aim of this study was to evaluate the longevity of the bond to superficial and deep dentin; failure mode, hybrid layer micromorphology when using $\mathrm{TiF}_{4}$ at the concentrations of $2.5 \%$ or $4 \%$ in an aqueous solution for dentin pretreatment, or incorporated into the primer of a twostep self-etching adhesive system; the degree of conversion of adhesive systems containing $\mathrm{TiF}_{4}$, as well as the particle size, polydispersity index and zeta potential of the $\mathrm{TiF}_{4}$ solutions. The null hypotheses to be tested were: (1) short-term bond strength to dentin at different dentin depths, fracture mode and micromorphological features of the hybrid layer when using $2.5 \%$ or $4 \% \mathrm{TiF}_{4}$ incorporated into the primer or when using dentin pretreatment with $2.5 \%$ or $4 \%$ aqueous solutions of $\mathrm{TiF}_{4}$ would be similar; (2) the degree of conversion, particle size, polydispersity index and zeta potential of the two-step adhesive system would not be affected by the incorporation of $2.5 \%$ or $4 \% \mathrm{TiF}_{4}$ into the primer/aqueous solution.

\section{Materials and methods}

\subsection{Microshear bond strength test}

Fifty sound third molars were obtained after patient consent and approval by the local ethics committee (CAAE 46933615.3.0000.5374). The teeth were cleaned and stored in a $0.1 \%$ thymol solution until the beginning of the experimental phase, and for a period not exceeding six months.

The specimens were prepared according to the methodology presented by Zhang et al. [24]. Two sections, $2 \mathrm{~mm}$ thick (Fig. 1A) were first made along the longitudinal axis of the tooth to remove the lingual and buccal tooth tissues (Fig. 1A). The remaining middle portion of each crown was then sectioned in the middle part, along the same direction, to obtain two slabs (approximately $2.0 \mathrm{~mm}$ thick each) (Fig. 1B) from the same tooth.

The two slices obtained from each tooth were embedded in polyester resin (Massa Fix, Royal Polímeros Indústria e Comércio de Produtos Químicos Ltda, SP, Brazil). The dentin surfaces were planed with abrasive papers impregnated with 600 grit aluminum oxide (3M do Brasil, Sumaré, SP, Brazil) fitted to a water cooled, pneumatic rotary electric polishing machine (Ecomet 250, Buehler Ltda, Lake Bluff, IL, USA). The blocks were ultrasonically cleaned in deionized water for $10 \mathrm{~min}$. After this, one slice of each tooth, which corresponded to the time of $24 \mathrm{~h}$, and another slice from the same tooth, corresponding to the time of 180 days were identified, totaling 50 slices for each time interval. 


\begin{tabular}{|c|c|c|c|c|c|c|}
\hline $\begin{array}{l}\text { Group/abbreviation } \\
\text { lot number/ }\end{array}$ & $\begin{array}{l}\text { Number of slices } \\
\text { - time } 24 \mathrm{~h}\end{array}$ & $\begin{array}{l}\text { Number of slices } \\
\text { - time } 180 \mathrm{~h}\end{array}$ & Composition/pH & Treatment & $\begin{array}{l}\text { Protocol for } \\
\text { use }\end{array}$ & $\begin{array}{l}\text { Manufacturer (City, } \\
\text { State, Country) }\end{array}$ \\
\hline $\begin{array}{l}\text { Clearfil SE Bond/CL } \\
051553\end{array}$ & 10 & 10 & $\begin{array}{c}\text { Primer: } \\
\text { 10-methacryloyloxydecyl } \\
\text { dihydrogen phosphate } \\
\text { (MDP), 2-hydroxyethyl } \\
\text { methacrylate (HEMA), } \\
\text { hydrophilic dimethacrylate, } \\
\text { Camphorquinone, } \\
\text { N,N-Diethanol p-toluidine, } \\
\text { water } \\
\text { pH 1.76 } \\
\text { Bond: } \\
\text { 10-methacryloyloxydecyl } \\
\text { dihydrogen phosphate } \\
\text { (MDP); Bisphenol } \\
\text { A-diglycidyl dimethacrylate } \\
\text { (Bis-GMA); 2-hydroxyethyl } \\
\text { methacrylate (HEMA), } \\
\text { hydrophilic dimethacrylate, } \\
\text { Camphorquinone, } \\
\text { N,N-diethanol p-toluidine, } \\
\text { Silanized Colloidal Silica } \\
\text { pH 1.81 }\end{array}$ & $\begin{array}{l}\text { Application of 2-step } \\
\text { self-etching adhesive } \\
\text { system (without } \\
\text { incorporation of } \mathrm{TiF}_{4} \text { ) }\end{array}$ & $\begin{array}{l}\text { - Apply primer actively for } \\
\qquad 20 \mathrm{~s} \text {; } \\
\text { - Apply light jet of air; } \\
\text { - Apply bond; } \\
\text { - Light activation for } 10 \mathrm{~s}\end{array}$ & $\begin{array}{l}\text { Kuraray Medical Inc. (1621 } \\
\text { Sakazu, Kurashiki, } \\
\text { Okayama, Japan) }\end{array}$ \\
\hline $\begin{array}{l}\text { Pretreatment with } \mathrm{TiF}_{4} \\
\text { 2,5\% + Clearfil SE } \\
\text { Bond/T2.5\%/MKBR9299V/051553 }\end{array}$ & 53 & 10 & $\begin{array}{c}\text { Pretreatment: } 2.5 \% \mathrm{TiF}_{4} \text {, } \\
\text { distilled and deionized } \\
\text { water } \\
\text { pH } 1.04+\text { Primer + Bond }\end{array}$ & $\begin{array}{l}\text { Dentin pretreatment with } \\
\text { aqueous solution of } 2.5 \% \\
\mathrm{TiF}_{4} \text {, followed by } \\
\text { application of the two-step } \\
\text { self-etching adhesive } \\
\text { system (without } \\
\text { incorporation of } \mathrm{TiF}_{4} \text { ) }\end{array}$ & $\begin{array}{l}\text { - Apply pretreatment } \\
\text { actively for } 60 \mathrm{~s} ; \\
\text { - Apply primer actively for } \\
20 \mathrm{~s} \text {; } \\
\text { - Apply light jet of air; } \\
\text { - Apply bond; } \\
\text { - Light activation for } 10 \mathrm{~s} \text {. }\end{array}$ & $\begin{array}{l}\text { Sigma Aldrich (Saint Louis, } \\
\text { MO, USA)/Kuraray Medical } \\
\text { Inc. (1621 Sakazu, } \\
\text { Kurashiki, Okayama, Japan) }\end{array}$ \\
\hline
\end{tabular}




\section{Table 1 (Continued)}

\section{Group/abbreviation} lot number/

Number of slices Number of slices Composition $/ \mathrm{pH}$ - time $180 \mathrm{~h}$

Treatment

Manufacturer (City,

- time $24 \mathrm{~h}$

10

Pretreatment: $4 \% \mathrm{TiF}_{4}$,

Dentin pretreatment with - Apply pretreatment actively for $60 \mathrm{~s}$; Sigma Aldrich (Saint Louis, $4 \%$ + Clearfil SE Bond/T4\% MKBR9299V/ 051553

distilled and deionized

$$
\text { water }
$$

pH 0.87 + Primer + Bond

followed by application of

the two-step self-etching

adhesive system (without

incorporation of $\mathrm{TiF}_{4}$ )

2.5\% $\mathrm{TiF}_{4}$ incorporated into primer of Clearfil SE

Bond/T2.5\%P MKBR9299V/

051553

4\% $\mathrm{TiF}_{4}$ incorporated into

primer of Clearfil SE

Bond/T4\%P MKBR9299V/

051553
10

10

Primer

pH 1.82 + Bond

10
2.5\% $\mathrm{TiF}_{4}$ incorporated into
Application of the primer with $2.5 \% \mathrm{TiF}_{4}$ incorporate into it, followed by the

application of the bond of adhesive system (without incorporation of $\mathrm{TiF}_{4}$ )

$4 \% \mathrm{TiF}_{4}$ incorporated into primer

pH $1.61+$ Bond the two-step self-etching
Application of the primer with $4 \% \mathrm{TiF}_{4}$ incorporated into it, followed by

application of the bond of the two-step self-etching adhesive system (without incorporation of $\mathrm{TiF}_{4}$ )

- A Apply Primer actively for
$20 \mathrm{~s}$;
- Apply light jet of air; - Apply bond;
- Light activation for $10 \mathrm{~s}$.

- Apply primer with $\mathrm{TiF}_{4}$

incorporated into it actively

- Apply light jet of air; - Apply bond;

- Light activation for $10 \mathrm{~s}$.

Sigma Aldrich (Saint Louis, MO, USA)/Kuraray Medical Inc. (1621 Sakazu,

Kurashiki, Okayama, Japan) MO, USA)/Kuraray Medical Inc. (1621 Sakazu, Kurashiki, Okayama, Japan)

- Apply primer with $\mathrm{TiF}_{4}$ incorporated into it actively for 20 s;

- Apply light jet of air; - Apply bond;

Sigma Aldrich (Saint Louis, MO, USA)/Kuraray Medical Inc. (1621 Sakazu,

Kurashiki, Okayama, Japan) 


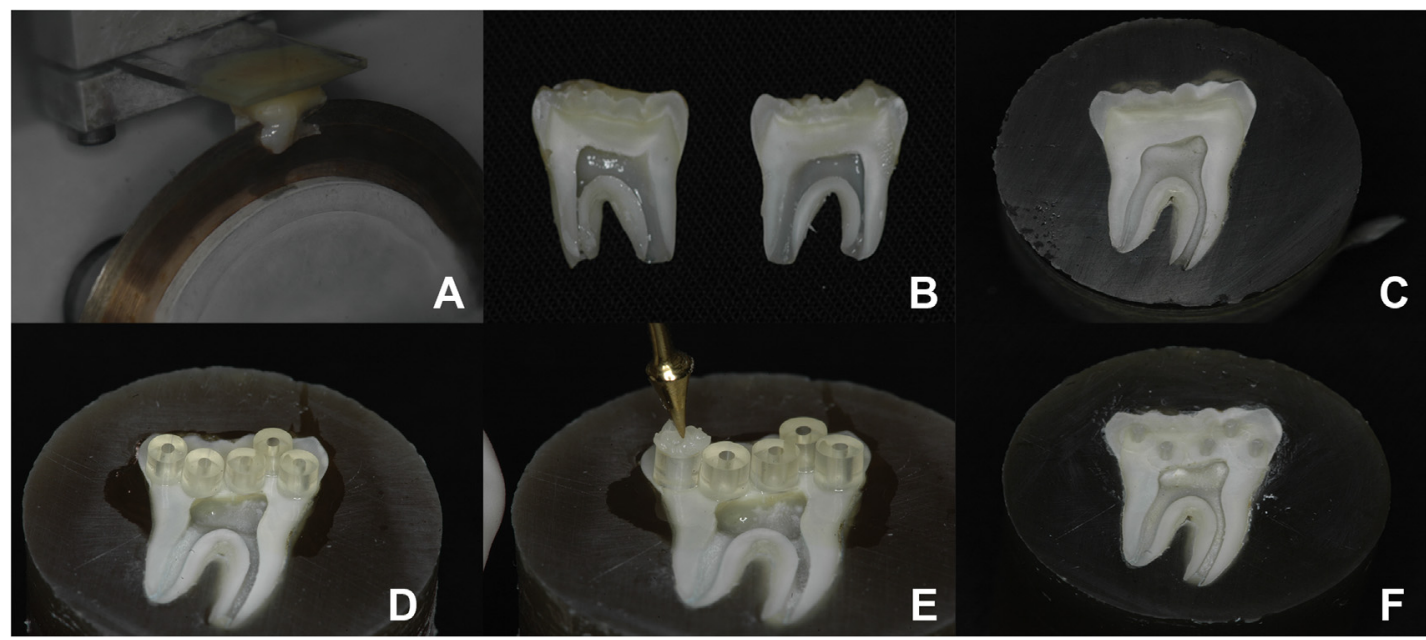

Fig. 1 - Specimen preparation for microshear bond strength evaluation in different depths of dentin (A) first sectioned along the longitudinal axis of the tooth; (B) two slabs obtained from the same tooth, by sectioning along the same direction as in A0; (C) one of the tooth slices embedded and planed; (D) superficial and deep dentin positioned in the tubes; (E) resin composite insertion into the tubes; (F) resin composite cylinders fabricated; please observe three cylinders corresponding to the superficial dentin region; and two cylinders, to the deep dentin region, after removal of the tubes.

The slices of each time interval were randomly divided into five groups, according to the adhesive treatments $(n=10)$ (Table 1).

In Group CL, the adhesive system was applied in accordance with the two-step self-etching adhesive system manufacturer (Clearfil SE Bond) (Table 1). For the T2.5\% and T4\% Groups, dentin pretreatment was performed with $2.5 \%$ or $4 \%$ titanium tetrafluoride. The titanium tetrafluoride was acquired in the pro-analysi (P.A.) form, and manipulated at the concentration of $2.5 \%$ or $4 \%$ in deionized distilled water (weight:volume) and applied as presented in Table 1. After pretreatment, the adhesive system was applied and light activated, in accordance with the manufacturer's instructions. For Groups T2.5\%P and T4\%P, the titanium tetrafluoride was acquired in the pro-analysi (P.A.) form, and manipulated at the concentration of $2.5 \%$ or $4 \%$ diluted in the primer (weight:volume) of the two-step self-etching adhesive system and was actively applied (rubbing) with a disposable paint brush as presented in Table 1.

The $\mathrm{pH}$ values of the aqueous solutions and primers manipulated with $\mathrm{TiF}_{4}$ in the different concentrations, and the primer and bond of the adhesive system used, were measured in triplicate with a microelectrode (Model 2A14, Analyser Instrumentação Analítica, São Paulo, SP, Brazil) and pH-meter (Model MPA 210, MS Tecnopon Instrumentação, Piracicaba, SP, Brazil).

On each slice, before the adhesive system was light activated, Tygon type microcylinders were positioned (internal diameter $0.8 \mathrm{~mm}$ and height $2 \mathrm{~mm}$ ) (Fig. 1D) in different localizations of the surfaces treated, denominated superficial dentin (DS) and deep dentin (DP). For the purpose of delimiting DS and DD dentin, the surface of the slab was marked by a line to delineate two zones of equal width to represent different dentin depths [24]. There was no way of placing the microcylinders tangentially to the roof of the pulp chamber or to the dentin-enamel junction, and leaving at least $1 \mathrm{~mm}$ distance from the roof of the pulp chamber or from the dentinenamel junction. After light activating the adhesive with a LED light appliance (Valo, Ultradent, South Jordan, UT, USA; wavelength range of $395-480 \mathrm{~nm}$ at an intensity of $1000 \mathrm{~mW} / \mathrm{cm}^{2}$ ), the hybrid resin composite (Filtek ${ }^{\mathrm{MR}} \mathrm{Z} 250 \mathrm{XT}, 3 \mathrm{M}$ ESPE, Irvine, CA, USA, shade A2, lot number: 228214) was carefully inserted into the tubes (Fig. 1E) and light activated at once to avoid influence of multiple light activations. Light activation was performed for $20 \mathrm{~s}$ - the time recommended by the resin composite manufacturer - by applying the light parallel to the long axis of the cylinder. In general, 3 cylinders were positioned in superficial dentin, and 2-3 cylinders in deep dentin (Fig. 1F).

After storage in artificial saliva at $37^{\circ} \mathrm{C}$ for $24 \mathrm{~h}$, the tubes belonging to the group that would be evaluated in the 24$\mathrm{h}$ time interval were carefully removed with a No.11 scalpel blade, leaving the resin composite cylinder apparent. For the group evaluated in the 180-day time interval, the test specimens were stored in individual receptacles in an artificial saliva solution ( $\mathrm{pH} 7 ; 1.5 \mathrm{mM}$ calcium; $0.9 \mathrm{mM}$ phosphorous; $0.15 \mathrm{M}$ potassium chlorate; $0.02 \mathrm{M}$ tris buffer) [25] that was changed on a weekly basis, to be tested after the storage period.

For the microshear bond strength tests, the blocks containing the tooth slices were fixed to the universal test machine device (Ez-LX 5 kN, Kyoto, Japan). The resin composite cylinders remained aligned to the load cell of $20 \mathrm{kgf}$. A stainless steel metal wire $0.2 \mathrm{~mm}$ in diameter was simultaneously looped around the prolongation of the machine load cell and one of the resin composite cylinders. The wire was kept in contact with the bottom semicircle of the cylinders as closely as possible to the area of the bond to the composite resin surface. A speed of $0.5 \mathrm{~mm} / \mathrm{min}$ was used, until fracture of the cylinder occurred. The values at the time of fracture were recorded in $\mathrm{N}$ and converted into $\mathrm{MPa}$. 


\subsection{Failure mode analysis}

The fracture type was evaluated under a stereoscopic lens (Model EK3ST, Eikonal Equip Ópticos e Analíticos, São Paulo, São Paulo, Brazil) at 20× magnification. The fracture types were classified into adhesive, cohesive in dentin or in resin, or mixed. The fracture types were classified as cohesive when there was predominance of over $50 \%$ of the fracture in the body of dentin, or body of resin; adhesive when over $50 \%$ of the failure occurred at the junction between the dentin and resin; and mixed when it was adhesive and cohesive at the same time. Representative images of the fractures were acquired by scanning electron microscopy (Phenom Pro X, Phenom-World BV, Eindhoven, Denmark) at 330 $\times$ magnification, used in standard mode under vacuum, and operating at a voltage of $10 \mathrm{kV}$.

\subsection{Micromorphological analysis of the hybrid layer}

Ten sound third molars were used to evaluate the hybrid layer interface in the region of superficial dentin region. For this purpose, flat occlusal surfaces were obtained in dentin by removing the portion of occlusal enamel perpendicular to the long axis of the tooth, with a diamond disc mounted in a precision electric cutting machine(Isomet 1000 Precision Diamond Saw, Buehler Ltd, Lake Bluff, Illinois, USA). The fragments were taken to a water-cooled, rotary polishing machine (Politriz Aropol 2 V, Arotec, Cotia, SP, Brazil), with the use of 600 grit aluminum oxide abrasive papers (Imperial Wetordry, $3 \mathrm{M}$, Sumaré, SP, Brazil).

After this, the teeth were divided among the groups, according to the five adhesive treatments $(n=2)$ (Table 1$)$. After application of the adhesive treatments one resin composite block (Filtek Z350, 3 M ESPE, Saint Paul, MN, USA) measuring $4.0 \mathrm{~mm}$ high and $4.0 \mathrm{~mm}$ wide was fabricated on the tooth by the incremental technique. The first layer, approximately $2.0 \mathrm{~mm}$ thick was placed and light polymerized for $40 \mathrm{~s}$. The second layer was placed and was also light activated for $40 \mathrm{~s}$. After this, the resin was light activated for $20 \mathrm{~s}$ on each of its two sides.

The dentin/resin composite block sets were fixed onto acrylic plates for position in a metallographic cutting machine (Isomet 1000 Precision Diamond Saw, Buehler Ltd, Lake Bluff, Illinois, USA) to cut sections approximately $1 \mathrm{~mm}$ thick in the vestibular-lingual direction. One section of each tooth was prepared for analysis by scanning electron microscopy [26], with planing being performed with decreasing $(400,600,1200)$ grits of aluminum oxide abrasive papers (Imperial Wetordry, $3 \mathrm{M}$, Sumaré, SP, Brazil) and polishing with diamond paste (Arotec SA Ind. E Com., Cotia, São Paulo, Brazil). After abundant rinsing, the specimens were demineralized, rinsed again, deproteinized, dehydrated in ethanol, chemically dried with HMDS (hexamethyldisilazane) and mounted on aluminum stubs. The specimens were examined by scanning electron microscopy (Phenom Pro X, Phenom-World BV, Eindhoven, Denmark), used in standard mode under vacuum, and operating at a voltage of $10 \mathrm{kV}$. The entire extent of the bond interface of each specimen was carefully scanned at 500× magnification. After this, the most representative area of each specimen was photographed at $1500 \times$ magnification. The interface morphology was analyzed in relation to hybrid layer formation, by analyzing its integrity and thickness, as well as presence, uniformity of size and disposition of resin tags.

\subsection{Degree of conversion analysis}

The degree of conversion of the primer solutions either containing $\mathrm{TiF}_{4}$, or not were dynamically analyzed by means of Fourier Transform Infrared Spectroscopy (FTIR, PerkinElmer Spectrum - One Fourier transform infrared spectrophotometer, Waltham, MA, USA) with resolution of $4 \mathrm{~cm}^{-1}$. The technique consisted of collecting the radiation reflected from the interface between the solution and crystal (ATR), showing the transformation of the double carbon bonds $(C=C)$ in the range of intensity of $1638 \mathrm{~cm}^{-1}$, in simple bonds $(C-C)$ in the range of $1608 \mathrm{~cm}^{-1}$

For each group, the quantity of $5 \mu \mathrm{L}$ of primer of the selfetching adhesive system Clearfil SE Bond (with or without $\mathrm{TiF}_{4}$ at the concentrations of 2.5 or $4 \%$ ) was deposited on the ATR crystal of the equipment, followed by the addition of $5 \mu \mathrm{L}$ of bond; the mixture between the components was performed with the use of an extra-fine disposable applicator brush (Cavibrush, FGM, Joinville, SC, Brazil) for the time of $10 \mathrm{~s}$. Radiation was analyzed by collecting the first 10 spectra, with the addition of the LED light activating appliance (VALO Curing Light, Ultradent Products Inc., South Jordan, Utah, USA) $10 \mathrm{~s}$, at a standardized distance of $2 \mathrm{~mm}$. The degree of conversion was monitored for $2 \mathrm{~min}$. The absorption-spectra were automatically collected by the equipment by means of the TimeBase (PerkinElmer) software, and saved in a format compatible with the Excel program for calculating the conversion data. The process of recording the spectra was repeated 5 times for each formulation, from which the mean degree of conversion was obtained for each experimental condition. The degree of conversion measurements were based on the baseline technique [27], in which:

$D C(\%)=\left(100-\left(\frac{\frac{1638 \mathrm{~cm}^{-1}}{1608 \mathrm{~cm}^{-1}} \text { polymerized }}{\frac{1638 \mathrm{~cm}^{-1}}{1608 \mathrm{~cm}^{-1}} \text { unpolymerized }}\right)\right) \times 100$

\subsection{Particle size, polydispersity index and zeta potential (colloidal stability) of incorporated solutions}

The aqueous solution of $\mathrm{TiF}_{4}(\mathrm{~T} 2.5 \%$ and $\mathrm{T} 4 \%$ ), the primer of Clearfil SE Bond (Primer CL), and the $\mathrm{TiF}_{4}$ incorporated into the primer (T2.5\%P and $\mathrm{T} 4 \% \mathrm{P})$ were analyzed relative to particle size, polydispersity index and zeta potential (colloidal stability). Dynamic light scattering was used to measure the size and size distribution of very small particles (nanoparticles) dispersed in a liquid (polydispersity index) [28]. The polydispersity index measures of the heterogeneity of sizes of molecules or particles in a mixture. Colloidal stability was investigated using an indirect procedure, based on the knowledge of the zeta potential, by means of the Helmholtz-Smoluchowski model [29]. These three properties were evaluated to study the distribution of the nanoparticles in the solution. The average particle size, polydispersity and zeta potential of the solutions were measured with the use of a Zetasizer Nano ZS (Malvern Instruments, Malvern, UK). 


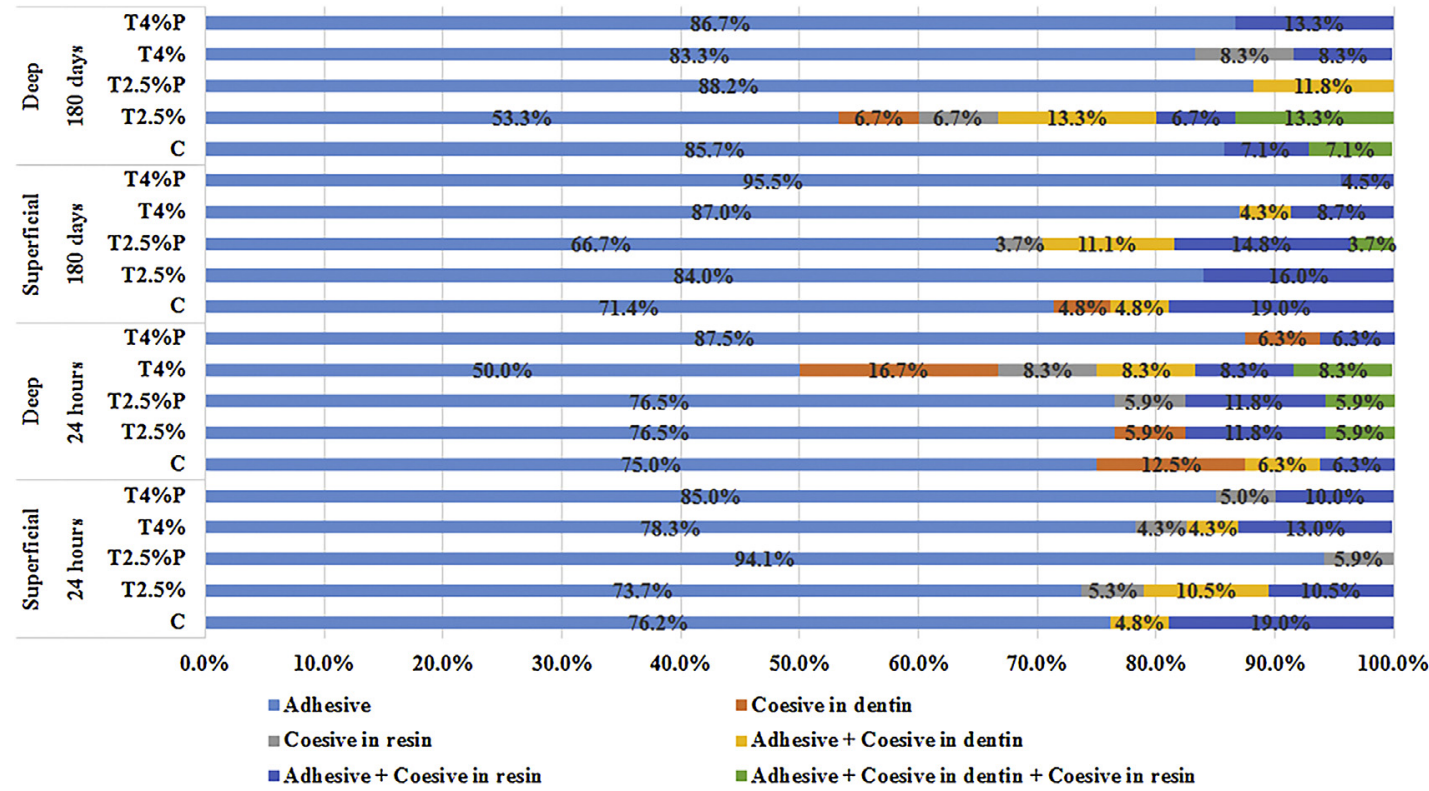

Fig. 2 - Distribution of frequencies of the fracture type considering the group, storage time and dentin depth.

The intensity of light scattered was used to calculate the mean hydrodynamic diameter (Z-average mean), based on the Stokes-Einstein equation, which assumes that the particle is spherical. The polydispersity index ranges from 0 to 1 . The larger the polydispersity index, the broader the molecular weight [30].

Zeta potential analysis was carried out using laser doppler electrophoresis with 20 runs per measurement at $25^{\circ} \mathrm{C}$. The zeta potentials were automatically calculated from the electrophoretic mobility using the Smoluchowski's approximation: $\mathrm{UE}=2 \times \varepsilon \times \mathrm{z} \times \mathrm{f}(\mathrm{ka}) / 3 \times \eta \rightarrow \mathrm{z} \approx \mathrm{UE} \times \eta / \varepsilon$, where $\mathrm{UE}$ is the electrophoretical mobility, $\varepsilon$ is the dielectric constant, $\mathrm{z}$ is the $\mathrm{ZP}, \mathrm{f}(\mathrm{ka})$ is Henry's function, and $\eta$ is the viscosity. This approximation is generally applied when the measurements are carried out in aqueous media, and it considers that Henry's function takes a value of $3 / 2$. The colloidal stability is determined by measuring electrophoretic mobility of the dispersed particles in the electric field applied. For each group, the analyses (particle size, polydispersity index and zeta potential) were performed in triplicate at $25^{\circ} \mathrm{C}$ immediately after preparation of the solutions.

\subsection{Statistical analysis}

The microcylinders that failed before the test (premature failures) were excluded from the analysis for evaluating the microshear bond strength, and the mean value of each tooth was considered according to the cylinders submitted to the tests at each depth and in each time. Exploratory analysis of the bond strength data indicated the removal of outliers belonging to Groups T2.5\%P - DS - 180 days, T4\%P - DS - $24 \mathrm{~h}$ and T4\%P - DP - 180 days. We applied the methodology of mixed models for repeated measures in the split plot design with factors assigned to the plot and additional treatments. Multiple comparisons were made with the Tukey-Kramer Test. The Exact Fisher Test was used to compare the fracture type between the groups. Exploratory analysis of the degree of conversion data indicated an outlier in the group with $\mathrm{T} 2.5 \% \mathrm{P}$. After removal of this value, one-way Analysis of Variance (ANOVA) was applied. Exploratory analysis indicated the logarithmic transformation for the polydispersity index and an outlier for average particle size (T2.5\%, at 28 days). The average particle size, polydispersity index and zeta potential were analyzed using mixed models for repeated measures in time (PROC MIXED), and multiple comparisons were performed using the Tukey Kramer test. The analyses were performed in the R (R Core Team 2015, Vienna, Austria) and SAS (Release 9.2, 2008, SAS Institute Inc., Cary, NC, USA) programs, considering the level of significance of $5 \%$.

\section{Results}

The percentage of premature microcylinder failures in the bond strength tests ranged from $6.9 \%$ to $40.0 \%$ (Table 2). When using dentin pretreatment with $4 \% \mathrm{TiF}_{4}$ aqueous solution on deep dentin, the percentage of premature failures (40\%) at both time intervals was higher than that of all the other groups.

Analysis of mixed models showed there was no interaction between the factors of $\mathrm{TiF}_{4}$ concentration $\times$ incorporation solution $\times$ dentin depth $\times$ storage time $(p=0.7395)$; incorporation solution $\times$ dentin depth $\times$ storage time $(p=0.4121) ; \mathrm{TiF}_{4}$ concentration $\times$ dentin depth $\times$ storage time $(p=0.8189)$; or between $\mathrm{TiF}_{4}$ concentration $\times$ incorporation solution $\times$ dentin depth $\times(p=0.9087)$. There was triple interaction between the factors of $\mathrm{TiF}_{4}$ concentration $\times$ incorporation solution $\times$ storage time $\times(p=0.0075)$, and the authors observed that there were significantly higher bond strength values for Group T4\%P at the 180 day time period for both dentin depths (Table 3). There were higher bond strength values 
Table 2 - Distribution of frequencies of premature fractures considering the group, time and dentin depth.

\begin{tabular}{|c|c|c|c|c|c|c|}
\hline \multirow[t]{2}{*}{ Time } & \multirow[t]{2}{*}{ Dentin depth } & \multirow[t]{2}{*}{ Treatment } & \multicolumn{2}{|c|}{ Premature failure } & \multicolumn{2}{|c|}{ Total } \\
\hline & & & $\mathrm{N}$ & $\%$ & $\mathrm{~N}$ & $\%$ \\
\hline \multirow[t]{10}{*}{$24 \mathrm{~h}$} & \multirow[t]{5}{*}{ SD } & CL & 5 & 19.2 & 26 & 100.0 \\
\hline & & $\mathrm{T} 2.5 \%$ & 7 & 26.9 & 26 & 100.0 \\
\hline & & $\mathrm{T} 4 \%$ & 4 & 14.8 & 27 & 100.0 \\
\hline & & $\mathrm{T} 2.5 \% \mathrm{P}$ & 5 & 22.7 & 22 & 100.0 \\
\hline & & T4\%P & 7 & 25.9 & 27 & 100.0 \\
\hline & \multirow[t]{5}{*}{ DD } & $\mathrm{CL}$ & 4 & 20.0 & 20 & 100.0 \\
\hline & & $\mathrm{T} 2.5 \%$ & 3 & 15.0 & 20 & 100.0 \\
\hline & & $\mathrm{T} 4 \%$ & 8 & 40.0 & 20 & 100.0 \\
\hline & & $\mathrm{T} 2.5 \% \mathrm{P}$ & 3 & 15.0 & 20 & 100.0 \\
\hline & & $\mathrm{T} 4 \% \mathrm{P}$ & 4 & 20.0 & 20 & 100.0 \\
\hline \multirow[t]{10}{*}{180 days } & \multirow[t]{5}{*}{$\mathrm{SD}$} & CL & 5 & 19.2 & 26 & 100.0 \\
\hline & & $\mathrm{T} 2.5 \%$ & 3 & 10.7 & 28 & 100.0 \\
\hline & & $\mathrm{T} 4 \%$ & 5 & 17.9 & 28 & 100.0 \\
\hline & & $\mathrm{T} 2.5 \% \mathrm{P}$ & 2 & 6.9 & 29 & 100.0 \\
\hline & & $\mathrm{T} 4 \% \mathrm{P}$ & 5 & 18.5 & 27 & 100.0 \\
\hline & \multirow[t]{5}{*}{$\mathrm{DD}$} & CL & 6 & 30.0 & 20 & 100.0 \\
\hline & & $\mathrm{T} 2.5 \%$ & 5 & 25.0 & 20 & 100.0 \\
\hline & & $\mathrm{T} 4 \%$ & 8 & 40.0 & 20 & 100.0 \\
\hline & & $\mathrm{T} 2.5 \% \mathrm{P}$ & 3 & 15.0 & 20 & 100.0 \\
\hline & & $\mathrm{T} 4 \% \mathrm{P}$ & 5 & 25.0 & 20 & 100.0 \\
\hline
\end{tabular}

Table 3 - Mean bond strength values in MPa (standard deviation) according to solution incorporated, concentration of $\mathrm{TiF}_{4}$, dentin depth and storage time.

\begin{tabular}{|c|c|c|c|}
\hline \multirow[t]{2}{*}{ Groups } & \multirow[t]{2}{*}{ Dentin depth } & \multicolumn{2}{|c|}{ Time } \\
\hline & & $24 \mathrm{~h}$ & 180 days \\
\hline \multirow[t]{2}{*}{ CL } & SD & "12.62 (2.69) A & ${ }^{*} 14.03$ (4.48) A \\
\hline & $\mathrm{DD}$ & 8.50 (3.96) A & 10.52 (4.30) A \\
\hline \multirow[t]{2}{*}{$\mathrm{T} 2.5 \%$} & SD & 11.30 (2.70) A & ${ }^{*} 13.35$ (4.56) A \\
\hline & $\mathrm{DD}$ & $9.80(3.26) \mathrm{A}$ & $10.57(2.12) \mathrm{A}$ \\
\hline \multirow[t]{2}{*}{$\mathrm{T} 4 \%$} & SD & *11.65 (3.11) A & ${ }^{*} 11.78$ (3.23) A \\
\hline & $\mathrm{DD}$ & $11.42(4.77) \mathrm{A}$ & $8.80(4.31) \mathrm{A}$ \\
\hline \multirow[t]{2}{*}{$\mathrm{T} 2.5 \% \mathrm{P}$} & $\mathrm{SD}$ & 10.61 (4.36) A & ${ }^{*} 11.23$ (2.72) A \\
\hline & $\mathrm{DD}$ & $9.63(3.90) \mathrm{A}$ & $9.93(3.42) \mathrm{A}$ \\
\hline \multirow[t]{2}{*}{$\mathrm{T} 4 \% \mathrm{P}$} & $\mathrm{SD}$ & 7.94 (1.35) B & "12.31 (4.47) A \\
\hline & $\mathrm{DD}$ & 7.00 (3.00) B & $11.39(3.25) \mathrm{A}$ \\
\hline
\end{tabular}

for superficial dentin than deep dentin $(p=0.0105)$ for all treatments at both storage time periods.

Fig. 2 shows the distribution of frequencies of the fracture type according to the storage time, dentin depth and group. The authors observed that a higher prevalence of adhesive type fractures occurred in most of the groups, irrespective of depth and time $(p=0.3746)$.

Fig. 3 presents a representative image of the fracture modes observed by scanning electron microscopy (SEM).

Evaluation of micromorphology (Fig. 4) showed that all the treatments promoted hybrid layer formation. The use of Clearfil SE Bond (Fig. 4A) led to the formation of longer and more voluminous resin tags, compared with the other treatments. When $\mathrm{TiF}_{4}$ was used in an aqueous solution as a pretreatment in the different concentrations, or incorporated into the primer, the authors verified uniformly distributed tags
Table 4 - Mean degree of conversion values in percentage (standard deviation) according to groups.

Concentration of $\mathrm{TiF}_{4}$ incorporated into primer

\begin{tabular}{ll}
\hline Absent & $76.74(6.49) \mathrm{A}$ \\
$2.5 \%$ & $77.66(1.69) \mathrm{A}$ \\
$4 \%$ & $76.43(3.00) \mathrm{A}$ \\
\hline
\end{tabular}

Means followed by equal letters do not differ among one another $(\mathrm{p}=0.9134)$.

throughout the entire hybrid layer, but of smaller diameter and depth (Fig. 4B-E).

One-way Analysis of Variance (ANOVA) showed that there were no significant differences in degree of conversion $(p=0.9134)$ between the groups (Table 4). 


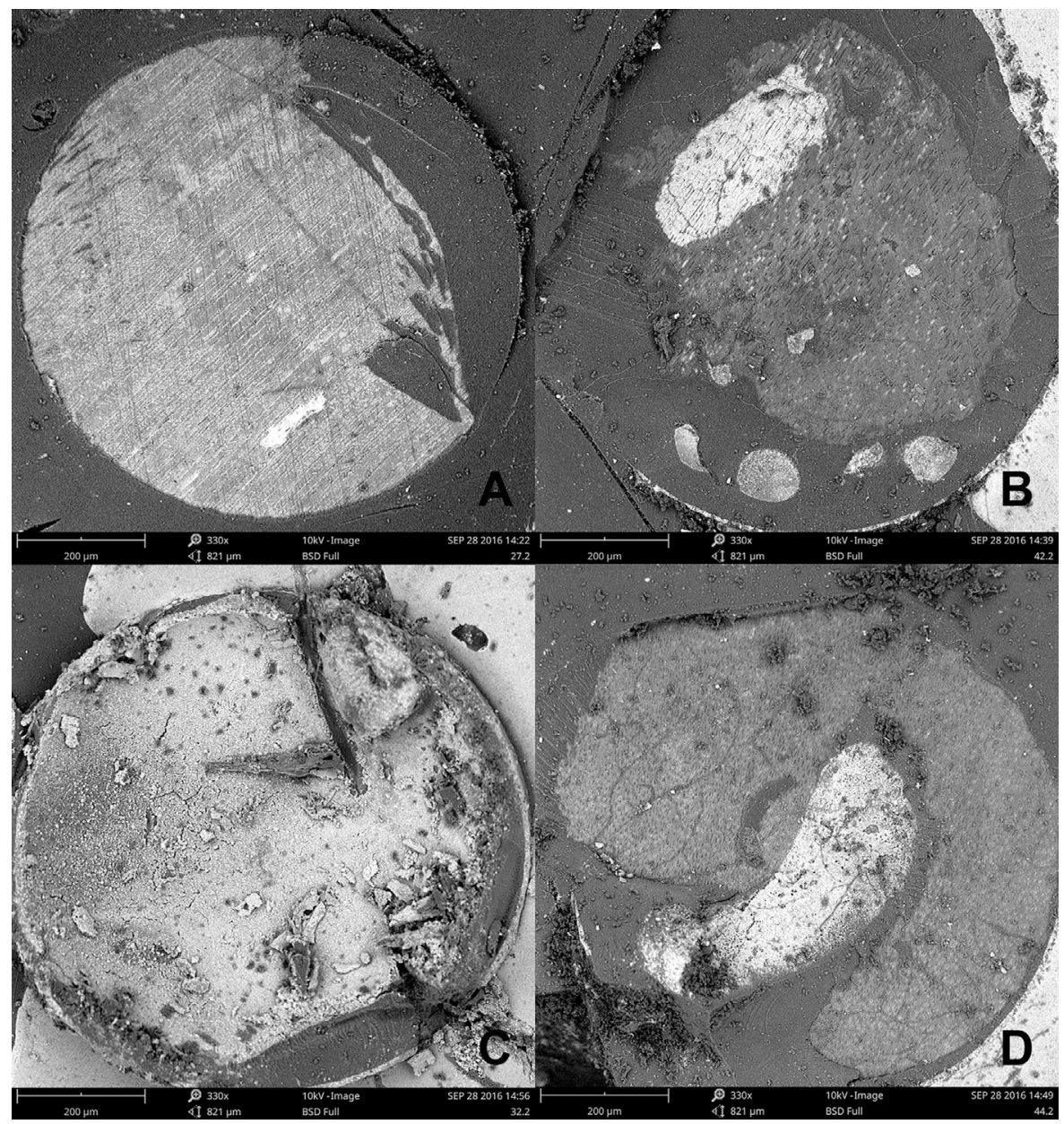

Fig. 3 - Images representative of the fracture modes observed by scanning electron microscopy (SEM). (A) Adhesive; (B) cohesive failure in dentin; (C) cohesive failure in resin; (D) mixed failure.

\begin{tabular}{|c|c|c|c|c|}
\hline \multirow[t]{2}{*}{ Analyses } & \multirow[t]{2}{*}{ Group } & \multicolumn{3}{|c|}{ Time } \\
\hline & & Baseline & 14 days & 28 days \\
\hline \multirow[t]{5}{*}{ Particle size (in nm) } & Primer CL ${ }^{*}$ & $277.87(4.45)$ Ac & 366.47 (18.85) Ac & $242.33(15.11) \mathrm{Ab}$ \\
\hline & T2.5\% & $569.03(27.64) \mathrm{Ca}$ & 1135.07 (133.08) Aa & $736.85(60.46) \mathrm{Ba}$ \\
\hline & $\mathrm{T} 4 \%$ & $406.70(23.58) \mathrm{Bb}$ & $704.40(44.90) \mathrm{Ab}$ & $671.20(35.61) \mathrm{Aa}$ \\
\hline & $\mathrm{T} 2.5 \% \mathrm{P}^{*}$ & $86.44(0.42) \mathrm{Ae}$ & 124.57 (1.21) Ad & $134.53(1.38) \mathrm{Ab}$ \\
\hline & $\mathrm{T} 4 \% \mathrm{P}$ & $199.97(0.81)$ Ad & 172.83 (2.27) Acd & $187.90(0.26) \mathrm{Ab}$ \\
\hline \multirow[t]{5}{*}{ Polydispersity index } & Primer CL & $0.42(0.04) \mathrm{Aa}$ & $0.39(0.02) \mathrm{Ab}$ & $0.33(0.01) \mathrm{Abc}$ \\
\hline & T2.5\% & $0.44(0.06) \mathrm{Ba}$ & $0.77(0.08) \mathrm{Aa}$ & $0.80(0.18) \mathrm{Aa}$ \\
\hline & $\mathrm{T} 4 \%$ & $0.34(0.04) \mathrm{Ba}$ & $0.64(0.31) \mathrm{Aab}$ & $0.52(0.02) \mathrm{ABab}$ \\
\hline & $\mathrm{T} 2.5 \% \mathrm{P}^{*}$ & $0.11(0.02) \mathrm{Bb}$ & $0.14(0.02) \mathrm{ABC}$ & $0.21(0.01)$ Acd \\
\hline & $\mathrm{T} 4 \% \mathrm{P}$ & $0.14(0.01) \mathrm{Ab}$ & $0.17(0.01) \mathrm{Ac}$ & $0.15(0.03) \mathrm{Ad}$ \\
\hline \multirow[t]{5}{*}{ Zeta potential (in $\mathrm{mV}$ ) } & Primer CL* & $-61.00(1.65) \mathrm{BC}$ & $-58.07(1.68) \mathrm{Ac}$ & $-58.17(0.59) \mathrm{ABC}$ \\
\hline & T2.5\% & $-9.32(0.24) \mathrm{Ba}$ & $-7.16(0.61) \mathrm{Ba}$ & $-3.92(1.05) \mathrm{Aa}$ \\
\hline & $\mathrm{T} 4 \%$ & $-6.80(0.38) \mathrm{Ba}$ & $-4.02(0.29) \mathrm{Aa}$ & $-3.32(1.22) \mathrm{ABa}$ \\
\hline & $\mathrm{T} 2.5 \% \mathrm{P}^{*}$ & $-60.30(2.10) \mathrm{Cc}$ & $-47.00(1.78) \mathrm{Bb}$ & $-43.83(0.93) \mathrm{Ab}$ \\
\hline & $\mathrm{T} 4 \% \mathrm{P}$ & $-44.73(1.59) \mathrm{Ab}$ & $-51.67(2.41) \mathrm{Bb}$ & $-48.47(2.83) \mathrm{Ab}$ \\
\hline
\end{tabular}

Means followed by different letters (lowercase in columns and uppercase in lines) differed statistically $(p \leq 0.05)$ for each analysis. * [14].

The interaction between the groups and the time periods yielded significant differences for the average particle size and zeta potential $(\mathrm{p}=0.0001)$ and for the polydispersity index $(p=0.0004)$. Lower average particle size values were observed for $\mathrm{T} 2.5 \% \mathrm{P}$, followed by $\mathrm{T} 4 \% \mathrm{P}$ at baseline, without differences over time. Higher average particle size values were observed 


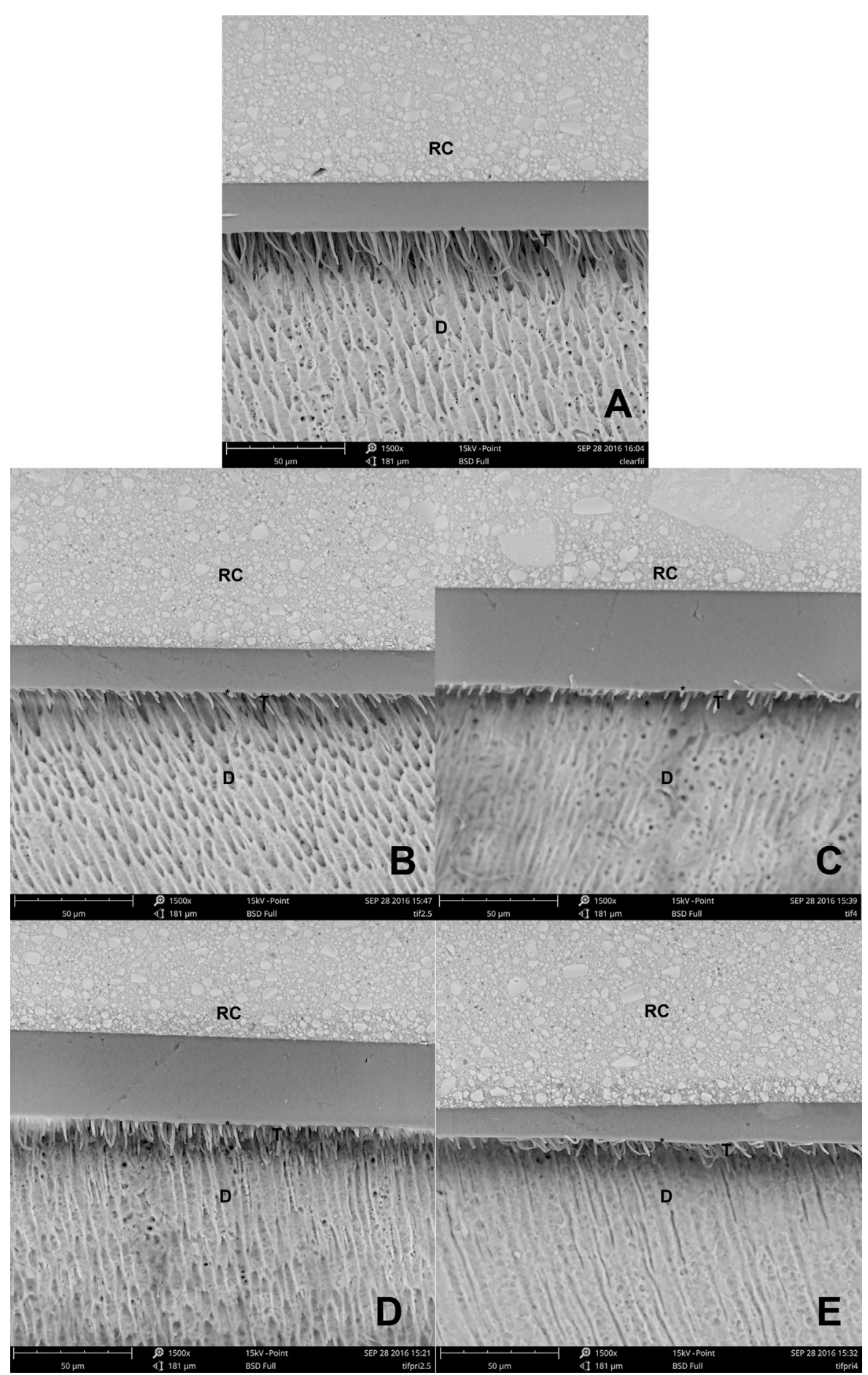

Fig. 4 - Photomicrograph of bond interface at 1500x magnification. (A) Hybrid layer formed after application of Clearfil SE Bond; (B) T2.5\%; (C) T4\%; (D) T2.5\%P; (E) T4\%P. RC - resin composite; * - hybrid layer; T - tags; D - dentin.

for the $2.5 \% \mathrm{TiF}_{4}$ aqueous solution (T2.5\%) at baseline and 14-day evaluation, and for both $\mathrm{TiF}_{4}$ aqueous solutions concentrations (T2.5\% and T45) at the 28-day evaluation (Table 5). Lower values were obtained for the polydispersity index at baseline and at 14 days for both concentrations of $\mathrm{TiF}_{4}$ in the primer, at all time points. However, the polydispersity index for $\mathrm{T} 2.5 \% \mathrm{P}$ increased over time, showing a mid-range value, meaning that the distribution algorithms work best over a number of benchmarks. The $2.5 \% \mathrm{TiF}_{4}$ aqueous solution showed very broad distribution of particle sizes at 14 days and 28 days of the study (values higher than 0.7) (Table 5). Zeta potential values were negative, showing that the nanoparticles were negatively charged. At baseline, lower zeta potential was observed for both concentrations of $\mathrm{TiF}_{4}$ aqueous solu- 
tion, and showed a trend toward agglomeration over time. $\mathrm{T} 2.5 \% \mathrm{P}$ showed a zeta potential value similar to that of $\mathrm{CL}$ Primer at baseline, increasing over time to a value not unlike that of $\mathrm{T} 4 \% \mathrm{P}$ at the 28 -day evaluation.

\section{Discussion}

In the present study, both aqueous solutions of $\mathrm{TiF}_{4}$ with concentrations of $2.5 \%$ and $4 \%$ used prior to a two-step selfetching adhesive system had no influence on bond strength to dentin in the immediate time interval. Although the aqueous solutions of $\mathrm{TiF}_{4}$ had low $\mathrm{pH}$ values (1.68 and 1.52 for the concentrations of $2.5 \%$ and $4 \%$, respectively), which causes them to be considered strongly acid etching agents, they themselves did not lead to dentin demineralization [4], but they promoted the formation of a titanium dioxide layer on the dentin surface, due to the chemical bond between titanium and the oxygen of the phosphate group of dentin [3]. Nevertheless, in spite of the moderate acidity of the Clearfil SE Bond adhesive system, it was effective in penetrating the vitreous layer formed by the application of the aqueous solution of $\mathrm{TiF}_{4}$ due to the acidity of the self-etching primer, thus allowing demineralization of the modified superficial dentin layer, leading to hybrid layer formation [12-14]. It should also be considered that the bond was favored by the presence of the hydrophilic functional monomer 10-MDP that significantly contributed to the chemical bond to dentin [31,32].

However, dentin pretreatment represents an additional step in adhesive procedures. Thus incorporation of the $\mathrm{TiF}_{4}$ into the self-etching primer was proposed with the purpose of simplifying the hybridization sequence with the benefits of using this agent as a dentin biomodifier [14]. From this aspect, when $\mathrm{TiF}_{4}$ was incorporated into the primer at the different concentrations, the authors observed no difference in the bond strength to dentin in the immediate time interval, not even when compared with the control groups, and when using $\mathrm{TiF}_{4}$ in an aqueous solution as pretreatment.

When incorporating $\mathrm{TiF}_{4}$ into the self-etching primer, attention must also be paid to the physico-chemical characteristics of the new material obtained, because the degree of conversion and $\mathrm{pH}$, as well as its mechanical properties may be changed. The percentage size and shape of particles may have a significant influence on the rheological properties of the resin materials $[33,34]$. However, the present study showed that the degree of conversion of the adhesive system when incorporating $\mathrm{TiF}_{4}$ into it at the different concentrations was not influenced, compared with the adhesive system without the incorporation of $\mathrm{TiF}_{4}$.

The size of the $\mathrm{TiF}_{4}$ molecule is $0.55 \mathrm{~nm}$ [15], which is much smaller than the nanoparticles of silica filler ( $7 \mathrm{~nm}$ on an average) [34] or the vitreous particles of $\mathrm{SiO}_{2}-\mathrm{BaO}(180-500 \mathrm{~nm}$ on an average, of each agglomerate) [35] that are generally used in adhesive systems. Studies have observed that the smaller the mean particle size, the greater the viscosity of the resin material [33]. Even considering the low concentrations of particles incorporated. The higher degree of viscosity has been attributed to the larger surface area of the smaller particles when compared with the same concentration of mass of large particles [34], which may impede their penetration into dentin.
However, it must be considered that the self-etching primer used did not contain an inorganic component (filler) and not even Bis-GMA in its composition. This may have compromised its diffusion into dentin to an even greater extent, due to the high molecular weight of the monomer and filler [36], because from a visual aspect, the viscosity of the primer into which $\mathrm{TiF}_{4}$ was incorporated at the different concentration did not appear to be affected. Furthermore, the fact of the primer containing hydrophilic monomers and water made it easy to incorporate and manipulate the material - contrary to what happens when incorporating these particles into the bond - allowing a higher level of diffusion on the dentin surface and favoring hybrid layer formation [14].

In fact, the addition of $\mathrm{TiF}_{4}$ to the aqueous solution at $2.5 \%$ or $4 \%$ showed that the attractive forces among particles exceeded the repulsion, and the dispersion flocculated, while the incorporation of $\mathrm{TiF}_{4}$ into the primer did not exhibit the trend towards agglomeration, especially at $2.5 \%$. The zeta potential measurements showed that the electrostatic potential of particles was directly related to their dispersion stability by the electrostatic repulsion. When the potential was small, attractive forces could exceed this repulsion and the dispersion could break and flocculate [37]. Similar zeta potential values were obtained for the $2.5 \% \mathrm{TiF}_{4}$ incorporated into the primer and Clearfil primer without incorporation, which meant that no agglomeration was observed, and they presented excellent stability and mid-range polydispersity index values, as was previously observed by Basting et al. [14]. Incipient stability was obtained for the aqueous solution of $\mathrm{TiF}_{4}$ at baseline for both concentrations, which decreased over time, showing rapid coagulation or flocculation at 28 days and a non-uniform dispersity. These results corroborated the average size particle values, as aqueous solutions of $\mathrm{TiF}_{4}$ presented the higher particle size values (mean of 569.03 for T2.5\% and 406.70 for $\mathrm{T} 4 \%$ at baseline), while $2.5 \%$ and $4 \% \mathrm{TiF}_{4}$ incorporated into the primer showed the lowest values at all time points, without differing from Clearfil Primer at 28-days evaluation. The authors hypothesized that $\mathrm{TiF}_{4}$ would be more stable in a primer formulation than in water, due to the initial $\mathrm{pH}$ of the natural water and the primer solutions. The acidity presented by the solutions is a result of the process of hydrolysis of $\mathrm{TiF}_{4}$, which releases titanium dioxide and fluoride; the fluoride released reacts with the water present in the solution itself, and releases $\mathrm{H}+$ protons, which characterizes the low $\mathrm{pH}$ values of the solutions $[38,39]$. The $\mathrm{pH}$ of the distilled and deionized water used in this study was around 6.0-6.5. However, the primer was an acidic solution with a $\mathrm{pH}$ of 1.76. Most likely, the hydrolysis of $\mathrm{TiF}_{4}$ in an acid solution would provide better stability and polydispersity of the end solution (obtained after incorporating the $\mathrm{TiF}_{4}$ in the water and the primer). Although just speculative, this explanation could account for the differences in stability between $\mathrm{TiF}_{4}$ solutions, and warrants further investigation. An increase in average particle size was observed for the $\mathrm{TiF}_{4}$ incorporated into the primer, followed by a trend of decreasing stability (from excellent stability at baseline to good stability at 28 days), for all mechanical and physical property evaluations (microtensile bond strength, failure mode, micromorphology of the interface, degree of conversion, flexural strength and $\mathrm{pH}$ measurements), even though the solutions were used 
immediately after preparation, when the chemical properties performed better. However, the null hypothesis that particle size, polydispersity index and zeta potential of the two-step adhesive system would not be affected by the incorporation of $2.5 \%$ or $4 \% \mathrm{TiF}_{4}$ into the primer/aqueous solution was partially accepted.

Studies have observed that the incorporation of particles into the hybrid layer may lead to an increase in energy occurring during failure, resulting in fracture propagation into substrates (in dentin or resin) other than the bond interface [35]. Tranquilin et al. [11] showed that the use of $2.5 \%$ $\mathrm{TiF}_{4}$ as dentin pretreatment led to an increase in the frequency of cohesive failures in dentin when the convention three-step adhesive system was used, shown by means of the microtensile bond strength test. Similarly, Devabhaktuni and Manjunath [10] observed higher frequency of cohesive and mixed failures in resin when using the shear test. However, in the present study, the majority of failures for all groups, irrespective of dentin depth was the adhesive type, corroborating the findings of Basting et al. [14] who used pretreatment with $\mathrm{TiF}_{4}$ or incorporated it into the primer of a two-step selfetching adhesive system. Therefore, the authors accepted the null hypothesis that the different concentrations of $\mathrm{TiF}_{4}$ used as pretreatment or incorporated into the primer would not change the failure mode of a two-step self-etching adhesive system bond to superficial or deep dentin.

Although the $\mathrm{TiF}_{4}$ particles were not silanized, which could have compromised occurrence of the chemical bond between the titanium and oxygen of the phosphate group of dentin, the authors verified that these particles did not prevent the degree of conversion of the adhesive system from occurring in a manner similar to that of the non-incorporated group, irrespective of its concentration in the primer, because it is the bond that contains the photoinitiator components of the setting reaction. On the other hand, incorporation of $\mathrm{TiF}_{4}$ into the bond could influence the degree of conversion of the adhesive, due to the reduction in $\mathrm{pH}$, thus compromising polymerization due to the tertiary amines of the adhesive - responsible for the photoinitiation process - being neutralized by the acidic properties of $\mathrm{TiF}_{4}$ [14].

The authors also observed that the bond strength of the two-step self-etching adhesive system to superficial dentin was higher than it was in deep dentin, even when we performed the dentin pretreatment procedures with the aqueous solution of $\mathrm{TiF}_{4}$ or when it was incorporated into the primer at the different concentrations. Therefore, the authors rejected the first null hypothesis. Other studies have demonstrated that self-etching adhesive systems present higher bond strength values to superficial dentin [40-43] due to the larger intertubular dentin area available to the adhesive procedure [18]. Since deep dentin has dentinal tubules with a larger diameter and smaller intertubular dentin surface area [18], the authors observed that the bond to deep dentin was inferior to that to superficial dentin, irrespective of whether or not there was pretreatment with $\mathrm{TiF}_{4}$ or its incorporation into the primer. Although very speculative and without any studies to prove this theory, it is quite possible that $\mathrm{TiF}_{4}$ molecules (even at the very low size of $0.55 \mathrm{~nm}$ [15]) would not reach dental pulp in distances deeper than $1-5 \mu \mathrm{m}$, since dentin demineralization promoted by $\mathrm{TiF}_{4}$ as a dentin pretreatment seems to provide limited superficial modification of $1-5 \mu \mathrm{m}$ of dentin depth [3]. Nevertheless, the application of $\mathrm{TiF}_{4}$ in dental cavities should be further investigated, considering that clinicians are advised to provide indirect pulp capping in very deep cavities using biocompatibility materials even before applying self-etching adhesive systems, and that $\mathrm{TiF}_{4}$ should be used with different protocols for direct pulp capping when the pulp is exposed, and also that only Şen et al. [44] showed that the toxic effect of $\mathrm{TiF}_{4}$ was related to its low $\mathrm{pH}$ when in contact with fibroblasts.

The authors speculated that the concentrations and distribution of MMP-2, MMP-9, TIMP-1 and TIMP-2, and the gelatinolytic potential of the dentin matrix were presented in a variable form at the different depths, which could lead to different collagen denaturing potentials [23]. Also associated with the above factors, was the process of hydrolysis of the adhesive systems that occurs due to their greater or lesser susceptibility to water/oral fluid sorption, composition and form of presentation, leading to plasticization [45-48]. In the present study, the authors verified that there was no influence of storage time, irrespective of dentin substrate depth, for the majority of the groups, with the exception of Group $4 \% \mathrm{TiF}_{4}$ in the primer, in which there was an increase over time, so the authors partially accepted the null hypothesis that there would be no differences in the longevity of the bond strength when using the different treatments on superficial or deep dentin. In spite of Zhang et al. [24] having verified that degradation of the hybrid layer of deep dentin was greater than it was in superficial dentin after artificial aging by means of thermal cycling, it must be considered that the conventional and self-etching adhesive systems evaluated were of the simplified type, as opposed to those used in the present study. Yoshida et al. [31] also showed that the chemical bond promoted by the monomer 10-MDP was stable in water compared with the other functional monomers, in addition to leading to the formation of a salt (MDP-Ca) that is resistant to hydrolysis $[49,50]$, thus contributing to greater bond longevity. From this aspect, when using this type of adhesive system, storage in water or artificial saliva showed no influence on the bond strength for periods of 6 months [51,52], 9 months [48] and 12 months $[14,47]$, and this period (just as that used in the present study) may also be considered short for evaluating the influence on bond longevity, with this being one of the limitations of our study.

Basting et al. [14] also verified that the storage time for 6 or 12 months did not influence the bond strength and failure mode when using Clearfil SE Bond, dentin pretreatment with $2.5 \% \mathrm{TiF}_{4}$ or incorporating it into the self-etching primer of the adhesive system, corroborating the results of the present study. Nevertheless, the authors observed that for the group in which $4 \% \mathrm{TiF}_{4}$ incorporated into the primer was used for both dentin depths, there was a significant increase in bond strength values over time, in spite of no differences in bond strength being observed between this Group in 180 days and the other groups in both evaluation time intervals. Considering the differences in dentin substrate depth, the author's also verified higher prevalence of premature bond failures when using pretreatment with $4 \% \mathrm{TiF}_{4}$ on deep dentin (40\%), suggesting some influence of the concentration on the immediate bond to the deeper substrate. From this aspect, the authors 
could suggest that for this concentration, there may have been less $4 \% \mathrm{TiF}_{4}$ penetration, or it may have been more difficult, due to the lower quantity of intertubular dentin [18], because the premature failure data were not accounted for in calculating the bond strength values, as they were excluded from statistical analysis so that the mean values for this group would not be underestimated.

Although further studies are necessary to evaluate other properties when using $\mathrm{TiF}_{4}$ as dentin pretreatment, or incorporated into the primer of a self-etching adhesive system, and the use of adhesives with known formulations, the authors could suggest that these treatments did not interfere in the bond to superficial or deep dentin, not even during the time interval of 180 days. Perhaps the incorporation of $\mathrm{TiF}_{4}$ into the primer in both concentrations could be more advantageous because of facilitating the clinical procedures of applying the product without involving a dentin pretreatment step; and it could also minimize the occurrence of premature failures in deep denting when using the pretreatment with the $4 \%$ concentration.

\section{Conclusion}

Short-term bond strength to dentin was not influenced by dentin pretreatment with $2.5 \%$ or $4 \%$ aqueous solutions of $\mathrm{TiF}_{4}$ or when using $2.5 \%$ or $4 \% \mathrm{TiF}_{4}$ incorporated into the primer, but bond strength values to superficial dentin were higher than values to deep dentin for all treatments. Degree of conversion was not influenced by the addition of $\mathrm{TiF}_{4}$ to the primer at different concentrations. The adhesive fracture mode was prevalent, although premature failures were observed for groups that received dentin pretreatment with aqueous solution of $4 \% \mathrm{TiF}_{4}$ on deep dentin. Hybrid layer formation was observed for all treatments, but fewer and less voluminous tags were observed for groups treated aqueous solution of $\mathrm{TiF}_{4}$ or when incorporated into the primer at both concentrations. $\mathrm{TiF}_{4}$ added to the aqueous solution in both concentrations showed a trend towards agglomeration over time, while $\mathrm{TiF}_{4}$ added to the primer presented an excellent stability and mid-range polydispersity index values, especially at $2.5 \%$.

\section{Disclosure statement}

The authors have no financial, economic, commercial, and/or professional interests related to topics presented in the manuscript.

\section{Acknowledgements}

The authors would like to thank FAPESP (Process Number 2015/06642-0) and CNPq (Process Number 307784/2015-0) for providing grants; to Vanessa Cavalli Gobbo and Marcelo Giannini who provided the tygon tubes for the microshear bond strength tests.

\section{REFERENCES}

[1] Bedran-Russo AK, Pashley DH, Agee K, Drummond JL, Miescke KJ. Changes in stiffness of demineralized dentin following application of collagen crosslinkers. J Biomed Mater Res B Appl Biomater 2008;86:330-4.

[2] Bedran-Russo AK, Pauli GF, Chen SN, McAlpine J, Castellan CS, Phansalkar RS, et al. Dentin biomodification: strategies, renewable resources and clinical applications. Dent Mater 2014;30:62-76.

[3] Sen BH, Büyükyilmaz T. The effect of $4 \%$ titanium tetrafluoride solution on root canal walls-a preliminary investigation. J Endod 1998;24:239-43.

[4] Basting RT, Leme AA, Bridi EC, Amaral FL, França FM, Turssi CP, et al. Nanomechanical properties, SEM, and EDS microanalysis of dentin treated with $2.5 \%$ titanium tetrafluoride, before and after an erosive challenge. J Biomed Mater Res B Appl Biomater 2015;103:783-9.

[5] Alcântara PC, Alexandria AK, Souza IP, Maia LC. In situ effect of titanium tetrafluoride and sodium fluoride on artificially decayed human enamel. Braz Dent J 2014;25:28-32.

[6] Alcântara PC, Alexandria AK, Souza IP, Maia LC. Energy dispersive $\mathrm{x}$-ray spectroscopy evaluation of demineralized human enamel after titanium tetrafluoride application. J Clin Pediatr Dent 2015;39:124-7.

[7] Magalhães AC, Rios D, Honório HM, Jorge Jr AM, Delbem AC, Buzalaf MA. Effect of $4 \%$ titanium tetrafluoride solution on dental erosion by a soft drink: an in situ/ex vivo study. Arch Oral Biol 2008;53:399-404.

[8] Magalhães AC, Rios D, Honório HM, Delbem AC, Buzalaf MA. Effect of $4 \%$ titanium tetrafluoride solution on the erosion of permanent and deciduous human enamel: an in situ/ex vivo study. J Appl Oral Sci 2009;17:56-60.

[9] Dündar M, Ozcan M, Cömlekoglu ME, Sen BH. Nanoleakage inhibition within hybrid layer using new protective chemicals and their effect on adhesion. J Dent Res 2011;90:93-8

[10] Devabhaktuni S, Manjunath M. Effect of $4 \%$ titanium tetrafluoride application on shear bond strength of composite resin: an in vitro study. J Conserv Dent 2011;14:43-5.

[11] Tranquilin JB, Bridi EC, Amaral FL, França FM, Turssi CP, Basting RT. TiF 4 improves microtensile bond strength to dentin when using an adhesive system regardless of primer/bond application timing and method. Clin Oral Investig 2016;20:101-8.

[12] Bridi EC, Amaral FL, França FM, Turssi CP, Basting RT. Influence of dentin pretreatment with titanium tetrafluoride and self-etching adhesive systems on microtensile bond strength. Am J Dent 2013;26:121-6.

[13] Domingues LG, Real CM, Bridi EC, Amaral FLB, França FMG, Turssi CP, et al. Effects of $2.5 \% \mathrm{TiF}_{4}$ on microtensile bond strength: influence of application method and degree of dentin mineralization. Int J Adhes Adhes 2014;54:159-64.

[14] Basting RT, Basting RT, Velarde Barrientos S, Bridi EC, França FM, Turssi CP, et al. Titanium tetrafluoride incorporated into a two-step self-etching adhesive system: physico-mechanical characterization and bonding stability. J Mech Behav Biomed Mater 2017;75:197-205.

[15] Nassur C, Alexandria AK, Pomarico L, Sousa VP, Cabral LM, Maia LC. Characterization of a new $\mathrm{TiF}_{4}$ and beta-cyclodextrin inclusion complex and its in vitro evaluation on inhibiting enamel demineralization. Arch Oral Biol 2013;58:239-47.

[16] Garcia EJ, Gomes OM, Gomes JC. In vitro analysis of bond strength of self-etching adhesives applied on superficial and deep dentin. Acta Odontol Latinoam 2009;22:57-62. 
[17] Özcan M, Mese A. Adhesion of conventional and simplified resin-based luting cements to superficial and deep dentin. Clin Oral Invest 2012;16:1081-8.

[18] Garberoglio R, Brännström M. Scanning electron microscopic investigation of human dentinal tubules. Arch Oral Biol 1976;21:355-62.

[19] Nakabayashi N, Pashley DH. Hybridization of dental hard tissues. Chicago: Quintessence; 1998.

[20] Carrilho MR, Carvalho RM, de Goes MF, di Hipólito V, Geraldeli S, Tay FR, et al. Chlorhexidine preserves dentin bond in vitro. J Dent Res 2007;86:90-4.

[21] García-Godoy F, Tay FR, Pashley DH, Feilzer A, Tjäderhane L, Pashley EL. Degradation of resin-bonded human dentin after 3 years of storage. Am J Dent 2007;20:109-13.

[22] Zhou J, Tan J, Chen L, Li D, Tan Y. The incorporation of chlorhexidine in a two-step self-etching adhesive preserves dentin bond in vitro. J Dent 2009;37:807-12.

[23] Niu LN, Zhang L, Jiao K, Li F, Ding YX, Wang DY, et al. Localization of MMP-2, MMP-9, TIMP-1, and TIMP-2 in human coronal dentine. J Dent 2011;39:536-42.

[24] Zhang L, Wang DY, Fan J, Li F, Chen YJ, Chen JH. Stability of bonds made to superficial vs. deep dentin, before and after thermocycling. Dent Mater 2014;30:1245-51.

[25] Serra MC, Cury JA. The in vitro effect of glass-ionomer cement restoration on enamel subjected to a demineralization and remineralization model. Quintessence Int 1992;23:143-7.

[26] Radovic I, Vulicevic Z, Radovic I, Vulicevic ZR, García-Godoy F. Morphological evaluation of 2- and 1-step self-etching system interfaces with dentin. Oper Dent 2006;31:710-8.

[27] Rueggeberg FA, Hashinger DT, Fairhurst CW. Calibration of FTIR conversion analysis of contemporary dental resin composites. Dent Mater 1990;6:241-9.

[28] Uskoković V. Dynamic light scattering based microelectrophoresis: main prospects and limitations. J Dispers Sci Technol 2012;33:1762-86.

[29] Zha LS, Li L, Bao LY. Synthesis and colloidal stability of poly(N-isopropylacrylamide) microgels with different ionic groups on their surfaces. J Appl Polym Sci 2007;103:3893-8.

[30] International Standard ISO22412. Particle size analysis dynamic light scattering. International Organisation for Standardisation (ISO); 2008.

[31] Yoshida Y, Nagakane K, Fukuda R, Nakayama Y, Okazaki M, Shintani $\mathrm{H}$, et al. Comparative study on adhesive performance of functional monomers. J Dent Res 2004;83:454-8.

[32] Van Landuyt KL, Snauwaert J, De Munck J, Peumans M, Yoshida Y, Poitevin A, et al. Systematic review of the chemical composition of contemporary dental adhesives. Biomaterials 2007;28:3757-85.

[33] Lee JH, Um CM, Lee IB. Rheological properties of resin composites according to variations in monomer and filler composition. Dent Mater 2006;22:515-26.

[34] Conde MC, Zanchi CH, Rodrigues-Junior SA, Carreño NL, Ogliari FA, Piva E. Nanofiller loading level: influence on selected properties of an adhesive resin. J Dent 2009;37:331-5.

[35] Belli R, Kreppel S, Petschelt A, Hornberger H, Boccaccini AR, Lohbauer U. Strengthening of dental adhesives via particle reinforcement. J Mech Behav Biomed Mater 2014;37: 100-8.

[36] Peutzfeldt A. Resin composites in dentistry: the monomer systems. Eur J Oral Sci 1997;105:97-116.

[37] Hanaor DAH, Michelazzi M, Leonelli C, Sorrell CC. The effects of carboxylic acids on the aqueous dispersion and electrophoretic deposition of $\mathrm{ZrO}_{2}$. J Eur Ceram Soc 2012;32:235-44.

[38] Tveit $A B$, Hals E, Isrenn $R$, Tøtdal B. Highly acid $S_{n} F_{2}$ and $\mathrm{TiF}_{4}$ solutions. Effect on and chemical reaction with root dentin in vitro. Caries Res 1983:412-8.

[39] Wahengbam P, Tikku AP, Lee WB. Role of titanium tetrafluoride $(\operatorname{TiF}(4))$ in conservative dentistry: a systematic review. J Conserv Dent 2011:98-102.

[40] Giannini M, Carvalho RM, Martins LR, Dias CT, Pashley DH. The influence of tubule density and area of solid dentin on bond strength of two adhesive systems to dentin. J Adhes Dent 2001;3:315-24.

[41] Pegado RE, do Amaral FL, Flório FM, Basting RT. Effect of different bonding strategies on adhesion to deep and superficial permanent dentin. Eur J Dent 2010;4:110-7.

[42] Villela-Rosa AC, Gonçalves M, Orsi IA, Miani PK. Shear bond strength of self-etch and total-etch bonding systems at different dentin depths. Braz Oral Res 2011;25:109-15.

[43] Bueno MFT, Basting RT, Turssi CP, França FMG, Amaral FLB. Effect of 2\% chlorhexidine digluconate application and water storage on the bond strength to superficial and deep dentin. J Adhes Sci Technol 2015;29:1258-67.

[44] Şen BH, Kazemi RB, Spangberg LSW. Morphological effects on L929 fibroblasts of titanium tetrafluoride application. Oral Surg Oral Med Oral Pathol Oral Radiol Endod 1998;86:341-6.

[45] Ito S, Hoshino T, Ijima M, Tsukamoto N, Pashley DH, Saito T. Water sorption/solubility of self-etching dentin bonding agents. Dent Mater 2010;26:617-26.

[46] Pashley DH, Tay FR, Breschi L, Tjaderhane L, Carvalho RM, Carrilho M, et al. State of the art etch-and-rinse adhesives. Dent Mater 2011;27:1-16.

[47] Marchesi G, Frassetto A, Visintini E, Diolosà M, Turco G, Salgarello S, et al. Influence of ageing on self-etch adhesives: one-step vs two-step systems. Eur J Oral Sci 2013;121:43-9.

[48] Zheng P, Zaruba M, Attin T, Wiegand A. Effect of different matrix metalloproteinase inhibitors on microtensile bond strength of an etch-and-rinse and a self-etching adhesive to dentin. Oper Dent 2015;40:80-6.

[49] Fukegawa D, Hayakawa S, Yoshida Y, Suzuki K, Osaka A, Van Meerbeek B. Chemical interaction of phosphoric acid ester with hydroxyapatite. J Dent Res 2006;85:941-4.

[50] Peumans M, De Munck J, Van Landuyt KL, Poitevin A, Lambrechts P, Van Meerbeek B. Eight-year clinical evaluation of a 2-step self-etch adhesive with and without selective enamel etching. Dent Mater 2010;26:1176-84.

[51] Freitas PH, Giannini M, França R, Correr AB, Correr-Sobrinho $\mathrm{L}$, Consani S. Correlation between bond strength and nanomechanical properties of adhesive interface. Clin Oral Investig 2017;21:1055-62.

[52] Manfroi FB, Marcondes ML, Somacal DC, Borges GA, Júnior LH, Spohr AM. Bond strength of a novel one bottle multi-mode adhesive to human dentin after six months of storage. Open Dent J 2016;10:268-77. 